QL

R25 the

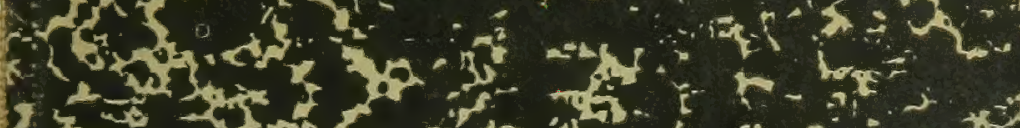

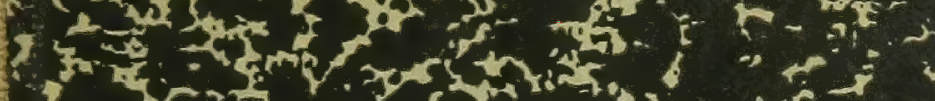
sind A I

(2)

a

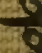

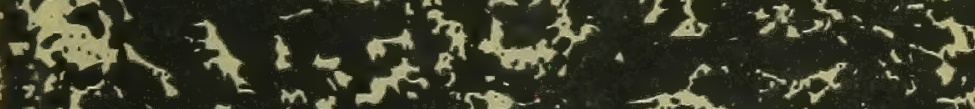

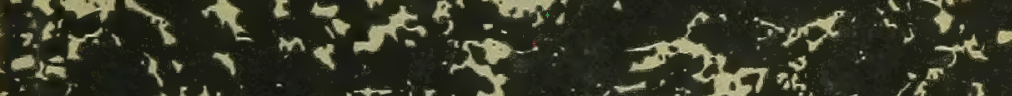

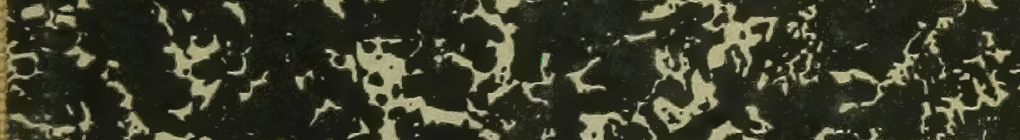

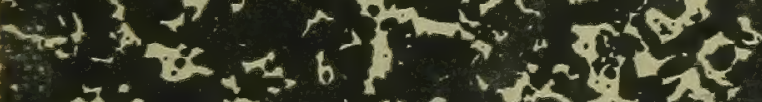
(15)

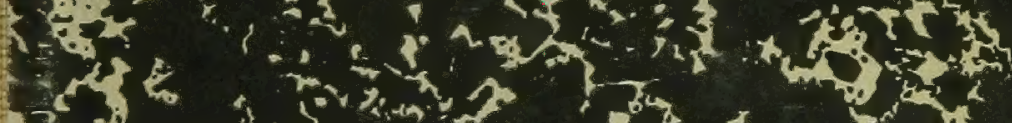

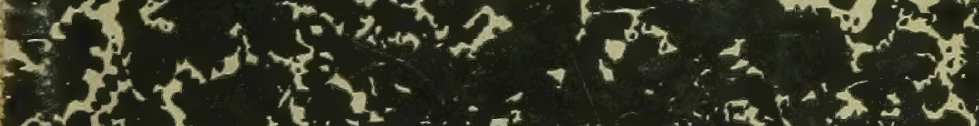

के

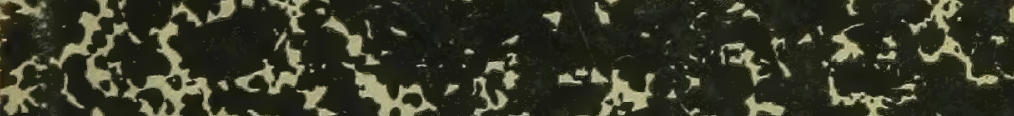

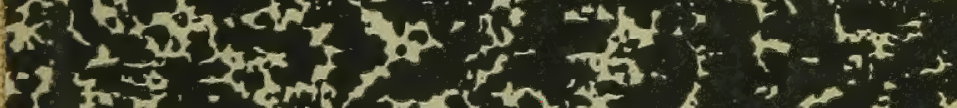
son (1)

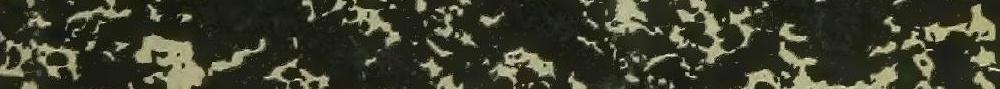

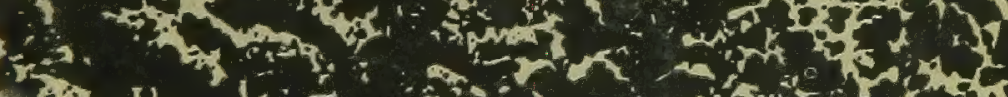
(3)

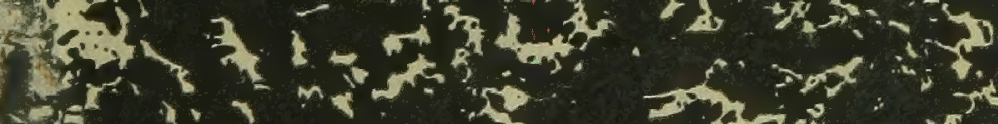
$\sqrt{3}$

2 at 100

(2) 


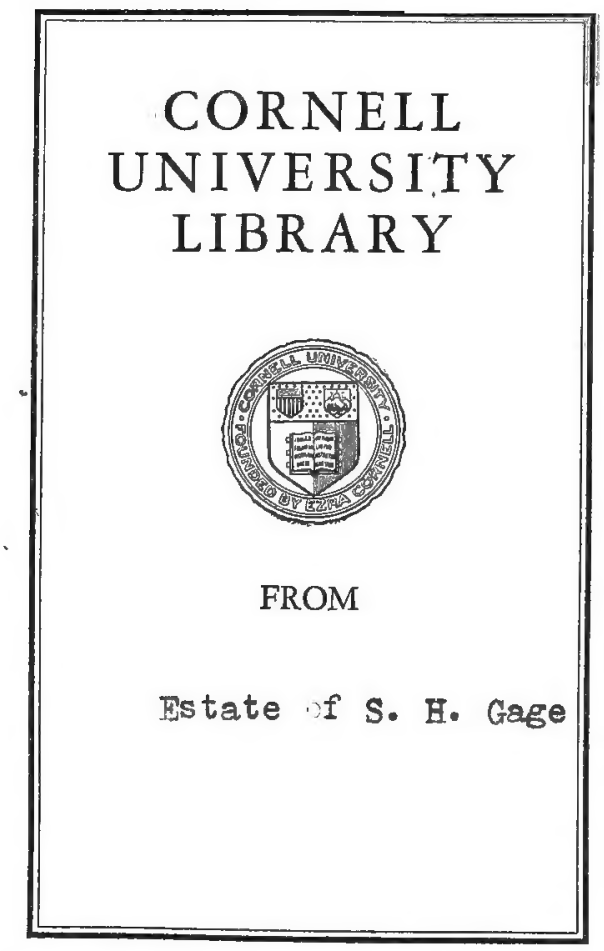

DEPARTMENT OF ZOÖLOGY 


\section{DATE DUE}

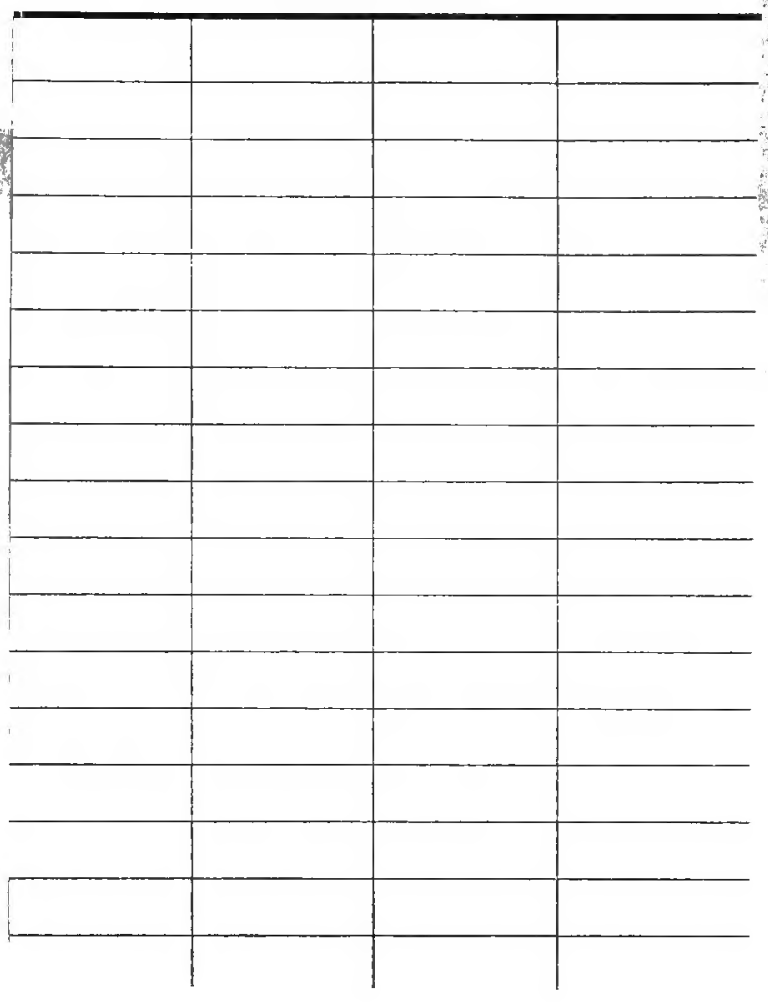

RETURN TO

\section{ALBERT R. MANN LIBRARY}

ITHACA, N. Y.

\section{Cornell University Library}

\section{Laboratory outlines for systematic verte}

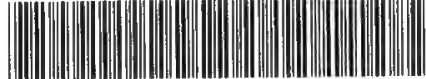

31924003393653 


\section{Cornell University Library}

The original of this book is in the Cornell University Library.

There are no known copyright restrictions in the United States on the use of the text. 


\section{LABORATORY OUTLINES}

FOR

\section{SYSTEMATIC VERTEBRATE ZOOLOGY}

REED and WRIGHT

ITHACA, NEW YORK

1914 



\title{
Laboratory Outlines for Systematic Vertebrate Zoology
}

\author{
Prepared by \\ H. D. REED and A. H. WRIGHT \\ Department of Zoology, Cornell University
}

ITHACA, NEW YORK

1914

KC 



\title{
Laboratory Outlines for Systematic Vertebrate Zoology
}

\author{
Prepared by \\ H. D. REED and A. H. WRIGHT \\ Department of Zoology, Cornell University
}

ITHACA, NEW YORK

1914

$\mathrm{Kc}$ 


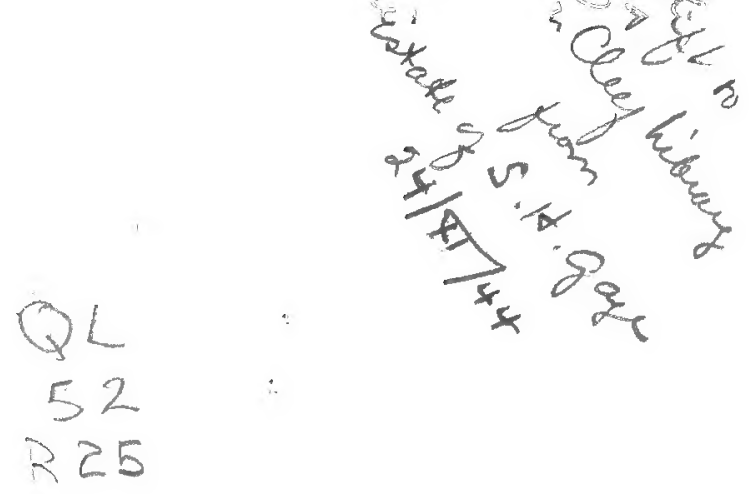

$$
Z, G=71
$$




\title{
Laboratory Outlines for Systematic Vertebrate Zoology
}

\author{
Prepared by H. D. Reed and A. H. WRIGHT
}

In order to follow the laboratory outlines, it will be necessary for each to bring to the laboratory the notes and drawings made in the lectures. All drawings should be made large, and never more than two on a sheet.

Each student should be supplied with both ruled and plain paper, $8 \times$ ro $1 / 2$ inches, and a pair of dividers. A good eraser and a medium hard pencil are essential for neat and accurate drawings. Results of observations and descriptions should be recorded upon the ruled sheets.

At the end of each week the notes are to be bound to the back cover of the portfolio and submitted for inspection.

Make and label drawings in pencil. After inspection they are to be "inked in" with India Ink. At the end of each term all of the notes are to be bound together and submitted for final inspection. Credit for laboratory work will be based upon the neatness and accuracy of the laboratory reports.

Definition of the Terms Used in the Following Outlines

Dorsum . ....... back.

Dorsal .... ...... . pertaining to the back.

Dorsad ... . ....... towards the back.

Venter .... ...... belly.

Ventral ........... pertaining to the belly.

Ventrad ... ........ toward the belly.

Cephalic .... ...... pertaining to the head.

Cephalad.... ...... toward the head.

Caudal .............. pertaining to the tail.

Caudad ...... ...... toward the tail.

Meson . ........... the imaginary plane which divides the body into equal right and left halves.

Mesal...... ...... . pertaining to the meson.

Mesad . . . . . . . . . . . . towards the meson.

Laterad ... . ........ away from the meson. 


\section{PISCES}

The Structures of the Yellow Perch,

\section{Perca flavescens}

I. External features:

(a). Form of body-Compare with the stone cat and the porgy. Compare the skin of the catfish and perch. Resilt?

(b). Lateral line-(For this study use the common white sucker.) A line on the side of the body extending from the head to the tail. Examine with a lens. Of what is this line composed? Trace the lateral line upon the head of the pike or a pickerel.

(c). Mouth-Is it terminal, superior, or inferior? Examine the mouth of a white sucker and of a stargazer. Which of the above terms applies?

(d). Barbels-Examine à catfish and the creek chub. The barbels are fleshy projections about the mouth. Does the perch possess such structures?

(e). Operculum-A flap on the side of the head covering the gills. Lift its caudal free margin to expose the gills.

(f). Branchiostegals and branchiostegal (or gill) membranes - Turn the specimen upon its back. Extending ventrad from the operculum is a membrane supported by curved rays. The membrane is the branchiostegal or gill membrane, and the rays are the branchiostegals. Determine their number. Write the formula.

(g). Isthmus-A narrow strip on the ventral side of the head, extending from the chin to the breast region. Are the gill membranes joined to it? Examine the white sucker. Result? Make a diagram of this

$\therefore \quad$ region in the perch and in the sucker. Examine this region in the bowfin, Amiatus, and note the ovoid gular plate between the rami of the lower jaw. Draw.

(h). Fins.

(1). Names, number and position.

(2). Types of tails.

(a). Heterocercal-Study and draw tail of the gar. 
(b), Homocercal-Study and draw tail of the halibut.

(c). Isocercal-Study and draw tail of the cod.

(d). To which type does the tail of the perch belong?

(3): Finlets-Small and flaglike fins of the dorsum and venter cephalad of the caudal fin. Examine a mackerel. Draw the tail region.

(4). Structure of fins.

(a). Types of fin-rays.

(I). Soft rays. Ask the instructor for a fin composed of soft rays. Note the method of branching and the joints. Make a drawing of a single ray.

(2). Spines. Ask for specimen.

Compare with soft ray. Result? Examine the first dorsal fin of the miller's thumb. To what type do the rays belong? Examine the brook stickleback and note the spines on the dorsum unconnected by membrane. These are termed free spines.

(3). Fulcra-Rudimentary spinelike projections on the cephalic margin of a fin. Examine the dorsal of the gar. Draw.

(4). Examine the dorsal fins of the common bullhead. Note that the last dorsal fin is reduced in size and lacks rays. Such a fin is knoẅn as an adipose fin. Compare the adipose fin of the bullhead 
and of the stone cat. In the former it is free, while in the latter it is said to be adnate to the back.

(b). Write the fin formulas of the perch.

(c). Make a table which will contrast the fins (including type of tail) of the perch, bullhead, stone cat, and gar.

(i). Types of scales.

(I). Placoid-Froma ray. Draw.

(2). Ganoid scales-Bony plates from the sturgeon; rhombic plates from a gar. Drawing of each.

(3). Cycloid-From white sucker. Study an ordinary scale and one taken from the lateral line. Drawing of each. Examine the scales of an eel. Make a drawing of the scale arrangement and an enlarged drawing of a single scale. Repeat for the burbot. What name is applied to each?

(4). Ctenoid-From the perch. Draw.

(j): Maxillaries-Flat, triangular bones forming the lateral margins of the upper jaw. Identify. Determine extent. Compare with the maxillaries of the whitefish, in which note the supplemental maxillary in the dorso-caudal angle. Draw. Examine the maxillary of the bullhead. Result?

Examine the maxillary of the porgy and note that it slips under the edge of the preorbital bone.

(k). Premaxillaries-Forming the cephalic margins of the upper jaws. Are they protractile, i. e., are they capable of being pulled cephalad leaving a groove over the top of the snout? Compare with the bullhead. Result?

(1). Snout-Distance from the tip of upper jaw to the front margin of eye.

(m). Caudal Peduncle - The region in front of the caudal fin. Compare the perch and the mackerel. What characters are found associated in the mackerel?

(n). Make a drawing of the left side of the perch. Represent the mouth open and the fins extended. When 
the margins of the fins are tom, represent them entire as in nature. Represent the actual number of rays in the dorsal and anal fins. Below the drawing write the technical and common names of the fish, the measurements, and the scale and fin formulas.

(o). Face bones of the perch. By reference to Fig. I, identify the following bones in the perch, after carefully removing the skin and muscles from this region: opercular bones, 24, 25, 26, 27; orbital ring, 49, 50; nasal, 5I; jaws, 28, 29, 30, 31, 32; "suspensorium," I7, I8, I9, 20, 2I, 22, 23 .

Make a drawing of the face bones of the perch.

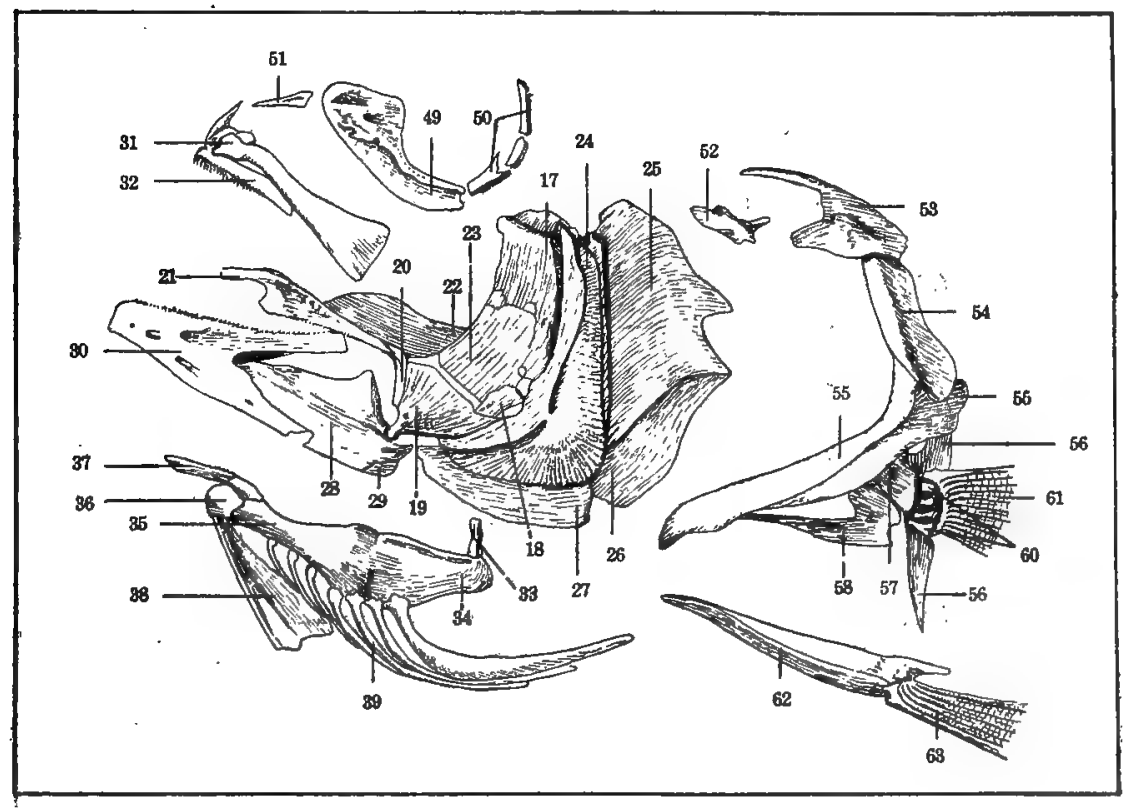

Fig. I. Face Bones of the Striped Bass, Roccus lineatus. (After Starks.)

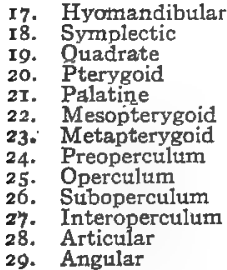

$\begin{array}{ll}\text { 30. } & \text { Dentary } \\ \text { 31. } & \text { Maxillary } \\ \text { 32. } & \text { Premaxillary } \\ \text { 33. } & \text { Interhyal } \\ \text { 34. } & \text { Epihyal } \\ \text { 35. } & \text { Ceratohyal } \\ \text { 36. } & \text { Basihyals } \\ \text { 37. } & \text { Glossohyal } \\ \text { 38. Urohyal } \\ \text { 39. } \text { Branchiostegal } \\ \text { 40. } \text { Preorbital } \\ \text { 50. } \text { Suborbitals }\end{array}$

5I. Nasal

52. Supratemporal

53. Posttemporal

54. Supraclavicle

55. Clavicle

56. Postclavicle

57. Hypercoracoid

58. Hypercoracoid

6o. Actinosts

6I. Pectoral rays

62. Pelvic girdle

63 . Ventral rays 
II. Internal features.

(a). Oral cavity-Expose by making a slit with the scissors from the corner of the mouth to the caudal angle of the operculum. Where do teeth occur?

(b). Types of teeth in fishes:

(r). Villiform-Study and draw teeth of the common bullhead.

(2). Setiform - Study and draw teeth of the black angel fish.

(3). Cardiform-Study and draw teeth of the common pike.

(4). Canine-Study and draw teeth of the walleyed pike

(5). Incisor-Studyand draw teeth of the sheepshead.

(6). Pavement-Study and draw teeth of the ray. Write formula.

(7). Coalescent-Study and draw teeth of the parrot fish.

(c). Oral breathing-valves-Folds of mucosa forming pockets just behind the teeth on both upper and lower jaws. Function?

(d). Vomer-This is a bone forming the middle of the roof of the mouth. Determine its location. Does it bear teeth? Examine a preparation of the brook trout in which the vomer is flat, and the lake trout in which this bone is boat-shaped.

(e). Tongue - Compare with the bullhead.

(f). Gill arches-Determine number, connections, and shape. Identify the gill rakers and gill filaments. Function of each. Write the formula for the gill rakers in the perch and whitefish, and make a drawing of each.

(g). Pseudobranchiae-Examine the inner surface of the operculum of the striped bass. Near the junction of the operculum with the preoperculum is a small gilllike structure, the pseudobranchia. When it is evident as in this species it is said to be exposed. When the pseudobranchia is not apparent, it is said to be concealed.

(h). Pharyngeal teeth-Located at the beginning of the esophagus. Upper pharyngeals, above the esophagus, and lower pharyngeals, below the esophagus. 
(I). Types of pharyngeal teeth:

(a). Falciform-Study the lower pharyngeals of the horned dace. Draw and write formula. Examine the lower pharyngeals of the white sucker in situ. Relation to the esophagus and gill arches?

(b). Molariform-Examine the upper and lower pharyngeals of the drum. Result? The lower pharyngeals of either side in this species are united at the middle. When found in this condition, they are said to be united below. Draw.

(c). Villiform-Borne on pads. Examine the bullhead. To which type do the pharyngeals of the perch belong?

(i). Abdominal viscera-Remove the ventral wall of the abdomen.

(1). Peritoneum-What is its color? Compare with the peritoneum of the stone-roller (Campostoma). Result?

(2). Identify stomach, liver, intestine, reproductive organs, and air bladder. What is the relation of the air bladder to the intestine? Compare with Campostoma. Result? What is the relation of the esophagus to the air bladder? Compare with the white sucker and bullhead. Result? What is the relation of the presence or absence of spines in the fins and the presence or absence of a duct between the esophagus and air bladder? Apply the terms Physostomi and Physoclysti in this connection

(3). Stomach-To what type does it belong? Are pyloric ceca present? Compare with the stomach of the bullhead and of the whitefish. Results?

(j). Vertebræ of fishes. Employ Fig. 2 in this study.

(I). Trunk or precaudal vertebra. Identify the following parts; centrum, neural arch, 
neural spine, zygopophyses. Are the vertebræ studied, of the amphicolian or opisthocoelian type?

(2). Tail or caudal vertebra. Compare with trunk vertebra and identify parts.

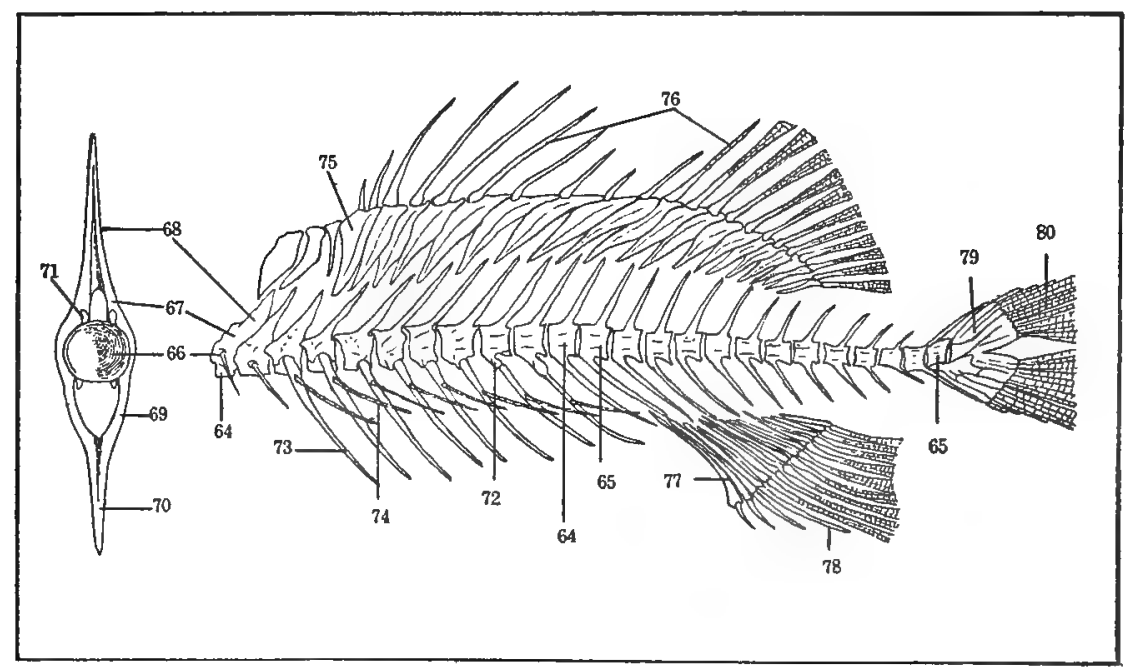

Fig. 2. The Trunk Skelton of the Striped Bass, Roccus lineatus. AFTER STARKS.
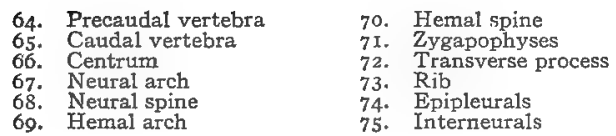
76. Dorsal rays and spines
77. Interhemals
78. Anal rays and spines
79. Hypural
80. Caudal rays

III. Fill out chart I according to the directions of the instructor. This is a summary of all the characters of classification considered in the foregoing study.

IV. Identification of representative species with the aid of a manual. Identification blanks will be employed for a record of the characteristics of the order, family, genus, and species. The number of the specimen is to be placed at the top of the sheet, and after the identification is completed, the technical and common names of the species are to be written on lines provided for the purpose. Remarks and drawings are to be made upon the lower half of the sheet. All specimens are to be identified. 
When the number of the specimen does not appear in the outline, it signifies that identification only is required.

Upon removing a specimen from the jar for study, dip it in water and keep it moist until returned to the alcohol. After the specimen is removed, cover the jar. Do not return jars to the shelf until the rubber gaskets and metal clamps are properly adjusted. The jars should be replaced according to their serial number.

(I). Make a drawing of the oral disk to show the supraoral lamina. From a medisected head, make a sketch of the nostril and nasal cecum.

(3). Make a drawing to show the differences of the sexes.

(6). Determine the sex. What are the short appendages on the dorsum of the snout?

(7). Examine a prepared skull, and note the fontanelle on the middle line of the dorsum.

(Io). Make a drawing of the left side of the head to show characteristics of the breeding male. Make a sketch of the dorsal fin to show one of the specific distinctions.

(II). Make a sketch of the ventral fin to show accessory scale.

(I6). Make a drawing of the left side of body.

(I7). Compare the head with that of a pickerel and a muskallunge. Make a drawing of the cheek and opercular region of each.

(22). Drawing of left side. Compare with the pipefish. Note opening of brood pouch in male.

(31). Make drawing of left side of head. Compare with small-mouthed black bass. Make a drawing.

(32). Young of number 3I. Make drawing of left side to show color pattern.

(37). Drawing of head and pectoral region. Note suborbital stay.

(38). Drawing of left side. Label parts.

(40). Drawing of the right side. Compare the lateral line with that of Paralichthys, in which this structure is strongly arched in front.

(4r). Jar of miscellaneous fishes to be identified, if time permits. 


\section{AMPHIBIA}

I. Study of the skull of the bullfrog.

(a). The skull of the frog, as in Amphibia generally, is broad and flat. It is composed of four divisions: The cranium or bones which surround the brain; the auditory capsules which lodge the internal ears; the olfactory capsules developed about the organs of smell; the jares and hyoid apparatus.

(b). Identify the following bones:

(I). The exoccipital bones are two irregular masses forming the caudal boundary of the cranial cavity. They bound the foramen magnum, through which passes the spinal cord, and articulate with the first vertebra by means of the occipital condyles, two oval convex processes.

(2). The fronto-parietals are two long flat bones, one on either side of the mesal line of the dorsum of the skull. They form the roof of the cranial cavity and are united at the meson. Caudad they articulate with the exoccipitals and prootics; cephalad with the sphenethmoid which they overlap. The lateral margins of the bones dip down into the orbits.

(3). The parasphenoid is a single bone on the ventral side of the skull forming the floor of the cranial cavity. It is cruciform in shape. The cephalic arm, which is longest, extends to and articulates with the palatines and overlaps the sphenethmoid. The transverse arms lie on the ventral surface of the exoccipitals and prootics. The caudal arm is short and triangular in shape.

(4). The sphenethmoid forms the cephalic boundary of the cranial cavity. It is overlapped by the fronto-parietals and nasals from above and by the parasphenoid and palatines below.

(5). The nasals are triangular bones on the cephalodorsal part of the skull. The cephalic por- 
tion of the bases of the triangles meet at the meson. The caudal portions diverge, thus enclosing, with the cephalic end of the frontoparietals, a diamond-shaped area in which the sphenethmoid is visible from the dorsum.

(6). The prootic bones are paired and form the caudal boundary of the orbits. Dorsad they articulate with the fronto-parietals; ventrad with the parasphenoid; caudad with the exoccipitals; laterad with the squamosals and pterygoids.

(7). The vomers are two triradiate bonies on the ventral surface of the skull within the triangular space formed by the palatines (behind), the maxillaries (at the sides), and the premaxillaries (in front). The mesocaudal arm of each bone bears a group of small pointed teeth. The internal nostrils (ental or internal nares) open between this and the lateral arm.

(8). The premaxillaries are two dentigerous bones which form the extreme cephalic margin of the upper jaw. They meet at the meson. There is a short process projecting from the dorsal edge of each bone.

(9). The maxillaries are two long curved bones forming the sides of the margin of the upper jaw. They are wide in front where they articulate with the premaxillaries, and narrower caudad.

(Iо). The quadrato-iugals are short, toothless, commashaped bones joined to the caudal end of the maxillaries and forming the extreme caudal margin of the upper jaw.

(II). The palatines are slender rodlike bones just caudad of the vomer. They extend laterad from the apex of the parasphenoid to the maxillaries.

(12). The pterygoids are triradiate bones on the ventral side of the skull. The inner arm is the shortest and is attached to the prootics. 
The cephalic arm is attached to the maxillary just caudad of the middle of its extent The caudal arm throughout its extent is attached to the ventral surface of the squamosal.

(I3). The squamosals are T-shaped bones visible on the dorsum of the skull. They form the articulation between the cranium and the lower jaw. Of the three arms of the $T$, the cephalic has a free pointed extremity, the upper caudal arm articulates with the prootic, the lower caudal arm (longest) extends downward and backward to unite with the caudal extremity of the quadrato-jugal.

(I4). The mentomeckelians are two small bones at the extreme cephalic portion of the lower jaw. They unite the two halves.

(15). The angulo-splenial is a strong bone forming the inner and ventral part of each half of the lower jaw. It articulates cephalad with the mentomeckelian; caudad with the squamosal and quadrato-jugal.

(16). The dentary is a thin plate of bone articulating with the mentomeckelian in front and joined to the outer surface of the cephalic half of the angulo-splenial.

(c). Make a drawing of the dorsum and venter of the skull, and label all the bones. Represent sutures by heavy lines.

II. Identification of species. Caution. Jars containing eggs must be handled carefully. Please refrain from touching prepared skulls with pencils or instruments. Dried skulls of salamanders and lizards are very fragile, and, therefore, easily destroyed. Do not handle salamanders and lizards by the tail. Place them in the jars, tail first.

(I). Make a drawing of the left side.

(2). Make a drawing of the left side.

13). Make a drawing of the left side.

i). Eggs of No. 3. Note the membranous projections from opposite sides of the eggs. In nature, the eggs are 
joined in strings by these projections. Make a drawing representing several eggs connected.

(5). Make a drawing of the left side.

(6). Make a drawing of the left side.

(12). Make outline sketches of the dorsum and venter of the skull, and compare with the skull of No. 8. Point out the distinctive features. In tracing the specimen to its family, you will find names for the distinctive structures. These constitute family characters. This jar contains both male and female. Note that in the male, the vent is swollen; the legs are wider and stronger than those of the female; the palmar surface of the toes and the inner side of the ankle possess patches of a dark horny substance. These are secondary sexual characters and aid the male in holding the female while mating. The patches are present only during the breeding season. The tail crest of the male is much larger than that of the female.

Make a drawing of the sole of the foot and the inner side of the leg, and of the lateral aspect of the tail and vent of both sexes.

(13). Eggs of No. I2. Make a drawing of the eggs and the plant to which they are attached.

(I5). Eggs of No. I4. Drawing of the egg-mass.

(ז6). Specimens illustrating the larval and transformation periods of No. I4.

(a). Mature larva. Drawing of the left side.

(b). Transforming larva. Note changes on the exterior, and draw the left side.

(I7). The shoulder girdle of the frog, illustrating the type found in the Firmisternia. The girdle is here considered as composed of an axial portion and two lateral portions or wings.

(a). The axial portion-The episternum is a spadeshaped piece of calcified cartilage, and is the most cephalic of the axial pieces. Its edges are very thin and composed of unchanged hyaline cartilage. The xiphisternum is the most caudal of the axial elements; In shape 
and structure it is much like the episternum, except that it is larger and deeply notched at its caudal margin. The omosternum is an elongate bone narrowed at its middle and broadened at either end. Its céphalic extremity is articulated with the episternum. The sternum proper is attached to and extends cephalad from the xiphisternum. This bone is narrow in its middle, gradually broadening towards either end. Between the omosternum and the sternum extends a cartilage known as the epicoracoid cartilage. In old individuals, this is almost concealed by the mesal development of the clavicles and coracoids.

(b). The lateral portions or wings-The suprascapula is the most distal (dorsal when the girdle is in situ) element, and is trapezoidal in shape. The distal portion is composed of hyaline cartilage, while the proximal or mesal half is composed of bone. The scapula is articulated with the proximal end of the suprascapula. It is a flat, compact bone, contracted in the middle and wider at the ends. Mesally it is articulated with the clavicle and coracoid. Between the scapula and epicoracoid cartilage are two bones; the more cephalic is the clavicle, which is very narrow; the caudal one is the coracoid, contracted in the middle and very broad at its mesal end where it articulates with the epicoracoid cartilage. At its distal extremity it takes part with the scapula in forming the glenoid cavity for the articulation of the arm-bone (humerus).

Make an enlarged drawing of the ventral aspect, with the notched xiphisternum directed toward the bottom of the sheet.

(I8). The shoulder girdle of the common toad. This illustrates the type of girdle found among the Arcifera. 
Identify the bones according to the directions given in section I7. Make a drawing of the ventral aspect, noting any differences between this type of girdle and that found in the frog.

(I9). Sacrum (9th vertebra) of a frog-The lateral processes are known as diapophyses, which in the frog are cylindric or "not dilated." Make a drawing of the dorsal aspect. The centrum is on the ventral aspect, and the diapophyses point caudad.

(20). Sacrum of the common toad-This is an example of the dilated diapophyses. Draw the dorsal aspect.

(2x). Make a drawing of the sole of the right foot.

(26). Egg cluster of No. 25. Make a drawing of the cluster and the branch to which it is attached. Represent a few eggs as if in the periphery of the cluster to show the enveloping jelly and the relation of the eggs to each other. Do not remove the eggs from the jar. Compare with No. I5.

(27). A series of specimens to illustrate the larval development of the frogs and toads.

(a). On the left side of the body, below and behind the eye, is a cleft, the spiracle, opening through a thin walled tube. After the loss of the external gills, internal gills are developed and the respiratory stream passes in at the mouth, over the internal gills and out at the spiracle. Is the tadpole symmetrical with regard to the spiracle? Determine the nature and position of the vent. On either side of the vent note the rudiments of legs. Make a drawing of the left side of the specimen.

(b). Mouth parts of a tadpole. Examine the mouth of stage $a$ with a hand lens for the general arrangement of the parts. Note: the broad expanse of lips bordered by a fringe; the jaws covered by a horny substance; the rows of fine teeth on the lips above and below the mouth. With a microscope study more carefully the parts of a specimen mounted in balsam. Make an enlarged drawing. 
(c). The skin on the right side has been turned back to show the arm developing beneath. Make a drawing of the right side showing the arm and the leg.

(d). The arms have broken through to the exterior. The left projects through the spiracle; the right actually came through the skin. Noie that the arm holes are still evident (i.e., the skin has not yet united with that of the arms). What changes have taken place in the eyes, mouth, and tail crest? Draw the left side.

(e). Transformation stage. Note vestige of tail and scars of the arm holes. Make a drawing of the left side.

(29). Eggs of No. 28. In nature, two strings are deposited at the same time. Make a drawing showing the spiral twist of the string.

\section{REPTILIA}

I. Identification of species.

(I). Before identifying this specimen, make a study of the scutellation. Make a much enlarged drawing of the dorsal, lateral, and ventral aspects of the head. Identify and represent the following scutes (scales): frontal (vertical), large and unpaired on the middle of the dorsum of the head between the eyes; the supraoculars, one on each side of the frontal between it and the dorsal margin of the eye; the parietals, a pair of large plates immediately caudad of the frontal and supraoculars; the prefrontals, a pair of large plates immediately cephalad of the frontal; the internasals, a pair of plates cephalad of the prefrontals and between the nostrils; the rostral, a mesal plate fitted about the snout; the preorbitals (preoculars), a series of plates forming the cephalic boundary of the eye; the postorbitals (postoculars), a series of plates varying in number in different species and forming the caudal boundary of the eye; the suborbitals, when present, are continuous with the preorbitals 
and postorbitals, and form the ventral boundary of the eye; the nasals, two plates surrounding the nostrils and bordering dorsally on the prefrontals and internasals; in some species these plates are fused into one, in which case the nostril is said to "penetrate the nasal plate"; the loreals, one on either side between the preorbitals and nasals; the labials (supralabials), a long row of plates along the margin of the upper jaw, the temporals vary in number in different species, and are placed caudad of the postorbitals, between the parietals above and the labials below. The number and arrangement of these plates are emp'oyed in classification. For example, the formula "temporals I-2-2" indicates that there are three (vertical) rows of temporals, and that there is one plate in the first row behind the postorbitals, and two in each of the other rows. Write beneath the drawing the formula for the temporals of this species. The mental plate is unpaired, and, placed at the tip of the lower jaw. There are two pairs of submentals (geneials) directly caudad of the mentals on the ventral side of the head. The infralabials constitute a row along the edge of the lower jaw caudad of the mental. The ventral plates (abbreviated V.P., and sometimes called gasterosteges) are the large plates covering the ventral side of the body. The one directly in front of the vent and sometimes divided (bifid), is called the anal plate. It is ustally cresentic in form. The plates caudad of the vent on the under side of the tail are in pairs and called urosteges. In some snakes they are not found in pairs. The gulars are the small plates on the side of the throat between the infralabials, submentals, and ventrals.

Make a drawing of the ventral aspect in the region of the vent, showing urosteges, ventral and anal scutes.

(6). Make a drawing of the dorsum of the head. Label the scutes.

(7). Make a drawing of the left side of the head. The pit located between the eye and the nostril is the loreal pit. Compare the urosteges with those of No. I. Result? 
(I5). Make a drawing of the dorsum of the skull, showing orbits and temporal fossæ.

(16). Compare the skull with that of No. I5. Result?

(20). The body of turtles in encased in a bony box, the dorsal portion of which is called the carapace, and the ventral portion the plastron. Both carapace and plastron are covered with thin, horny scutes or shields. Before identifying the specimen, study the scutellation and make a drawing of both carapace and plastron.

(a). Carapace-The row of scutes forming the margin of the carapace are the marginals. The narrow marginal scute situated on the middle line above the neck is the nuchal. The two marginals above the base of the tail are the supracaudals. The scutes extending along the middle line of the back are known as the vertebrals. The costals are those scutes between the marginals and the vertebrals.

(b). Plastron-In the plastron are six pairs of scutes. The most cephalic pair, placed directly beneath the neck, are the gulars. The others named in order from the gulars caudad are: humerals, pectorals, abdominals, femorals, anals. Caudad of the arm, between the carapace and the plastron, is the axillary scute, and in a similar position cephalad of the leg is the inguinal. In some species both axillary and inguinal scutes are more numerous.

(2I). Drawings of the ventral and the lateral aspects.

(23). Drawings of the dorsal and ventral aspects.

(24.) Drawings of the ventral aspect.

(26). Drawings of the ventral and the lateral aspects.

(28). A jar of miscellaneous specimens to be identified if time permits. 


\section{AVES}

I. A study of the topography of a bird.

(a). Study a specimen for the purpose of determining the various external parts of a bird which are used in classification. Reference may be made to a wall chart or figure in the manual.

(b). Study a prepared specimen of a wing to determine the various groups of feathers and their relation to the segments of the wing. Drawing is optional.

(I). Primaries-Attached to the hand.

(2). Secondaries-Attached to the forearm.

(3). Tertiaries-Attached to the upper arm.

(4). Primary coverts-Covering the bases of the primaries.

(5). Secondary coverts-Covering the bases of the secondaries. These coverts exhibit three groups, and are named according to size and position, greater, middle, and lesser coverts.

(6). Under coverts - Covering the bases of the flight feathers on the under side of the wing. A special group of feathers growing from the axilla (arm-pit) are termed axillars.

(7). Scapulars-A group of feathers on the upper side of the wing growing from the shoulder region. They are opposite the axillars of the under side.

II. Identification of species.

(I). Drawings of the bill and the foot. Label parts. To what type does the tail belong?

(2). Make a drawing of the bill to show unguis or nail and the lamellæ along the edges.

(3). Draw lobate foot.

(4). Note the serrations on the caudal edge of the thin tarsus.

(5). Draw the bill with its cere, one foot, and the scutellate tarsus.

(6). Make a drawing of the foot which is of the perching type.

(7). Compare the bill with that of No. 2.

(8). Make a drawing of the totipalmate foot. Why so named? Note the position of the fourth toe.

(10). Drawing of the ventral side of the tail. 
(I I). Drawing of syndactyl foot. Why socalled?

(13). Drawing of zygodactyl foot. Why socalled?

(14). Note the tubelike nostril. Draw.

(24). Drawing of the foot.

(26). Drawings of the bill and the dorsum of the wing and tail. Note the arrangement of the toes.

(30). To what type does the tail belong?

(32). A good example of the seed-eating type of bill. Make drawing.

(38). To what type does the tail belong?

(45). The tarsus of this species is known as the booted tarsus. How does it differ from others? Draw.

(48). Drawing of the bill.

(53). A good example of the fly-catching bill. Note its width and rictal bristles.

(68). Make a drawing of the reticulate tarsus. How does it differ from the scutellate and booted types?

(86). Note the somewhat swollen and pitted end of bill. This is the sensitive type of bill used in probing in mud for food.

(88). Drawing of the head to show the frontal shield.

\section{MAMMALIA}

I. A study of the mammalian skull. Time will not admit of a careful study of the skull of any one species. Figures 3, 4, and 5 have, therefore, been introduced as an aid in the identification of skull characteristics. The study of the skull of any given species is optional with the student.

II. Identification of species. Write the tooth formula of each species identified.

(I). Draw the left side of the skull and label parts. Drawing of the foot. Examine a mounted female which shows the pouch in which the young are carried for a time after birth.

(2). Draw the lateral aspect of the skull to show the type of dentition.

(3). Compare the skull with that of No. 2. Result?

(4). Draw the lateral aspect of the skull. 


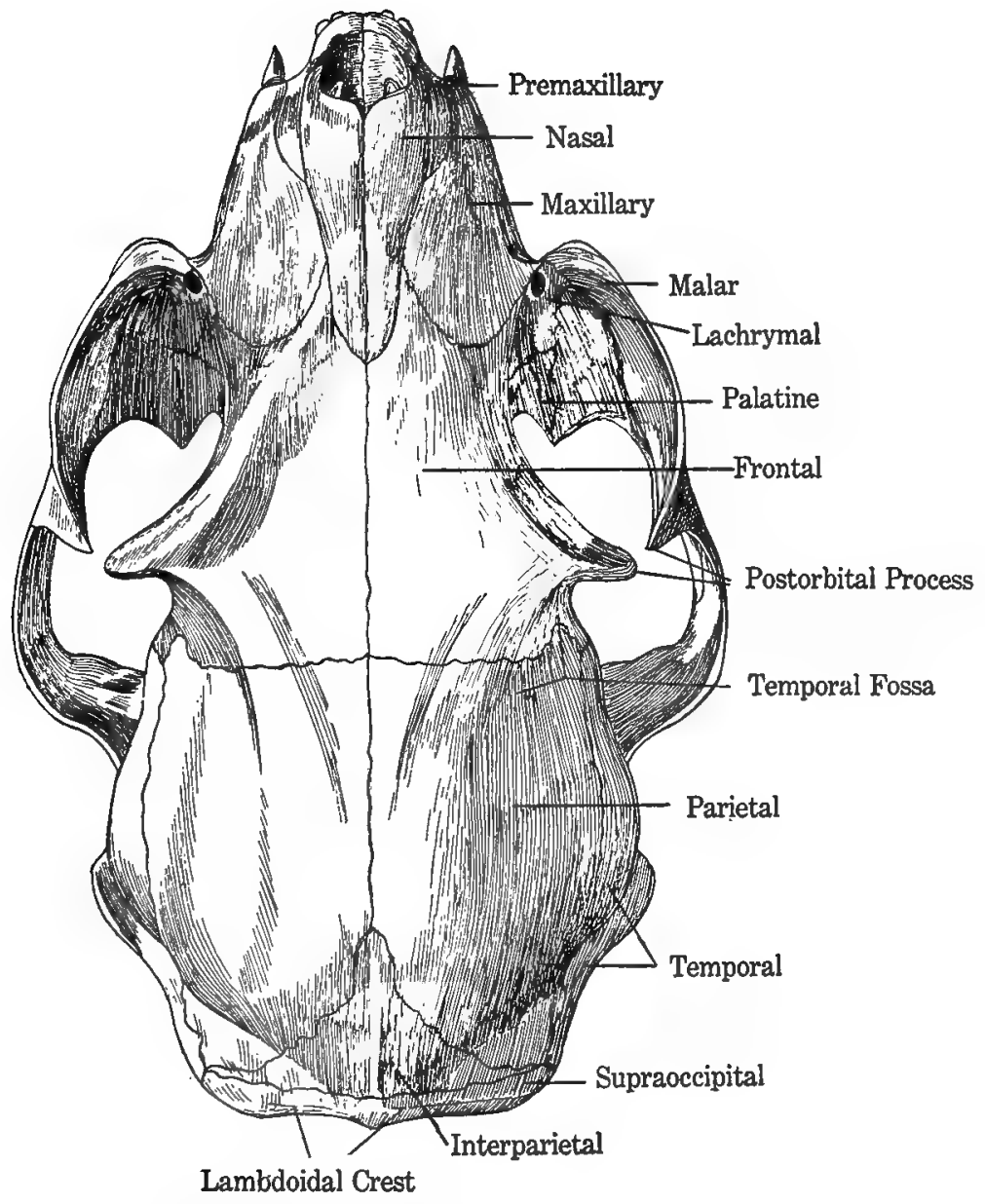

Fig. 3. Dorsal Aspect of the Cat's Skull. 
(6). Note the long muzzle. The dentition is of the insectivorous type. Compare with others already studied.

(7). Compare with No. 6. After identification of the species, correlate structure and habit. Drawings of characteristic features are optional.

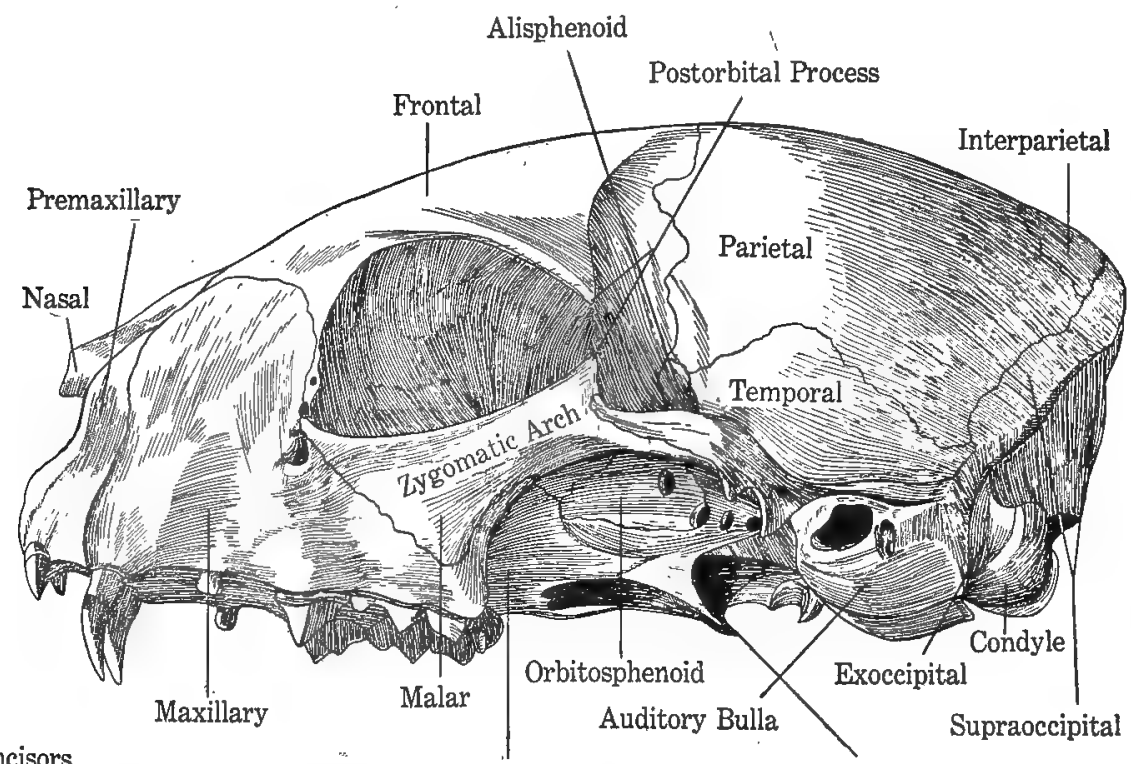

Incisors

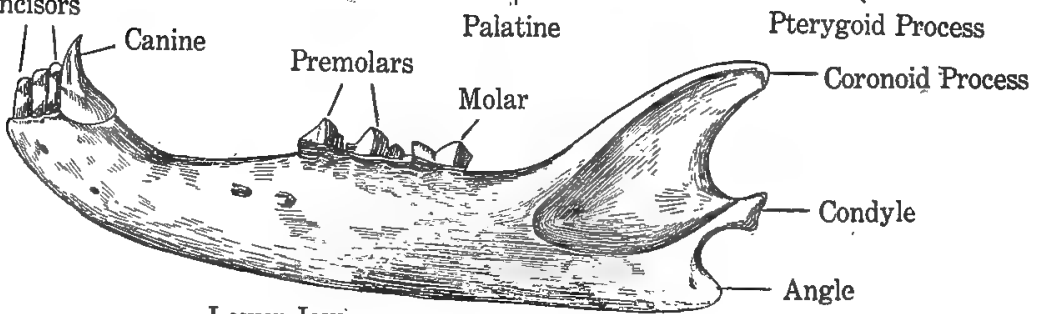

Lower Jaw

Fig. 4. Lateral aspect of the Cat's Skull.

(8). Make a diagram of the crown of a molar. Name the parts. Examine a tooth which has been extracted. Does it possess r oots or grow from a persistent pulp?

(9). Drawing of a skeleton of the right arm and name the bones. 
(io). Examine an extracted molar. Conclusion?

(I I). Note relative length of arms and legs. Conclusions?

(I2). Drawing of the left side of the skull. What are the characteristic features of the dentition?

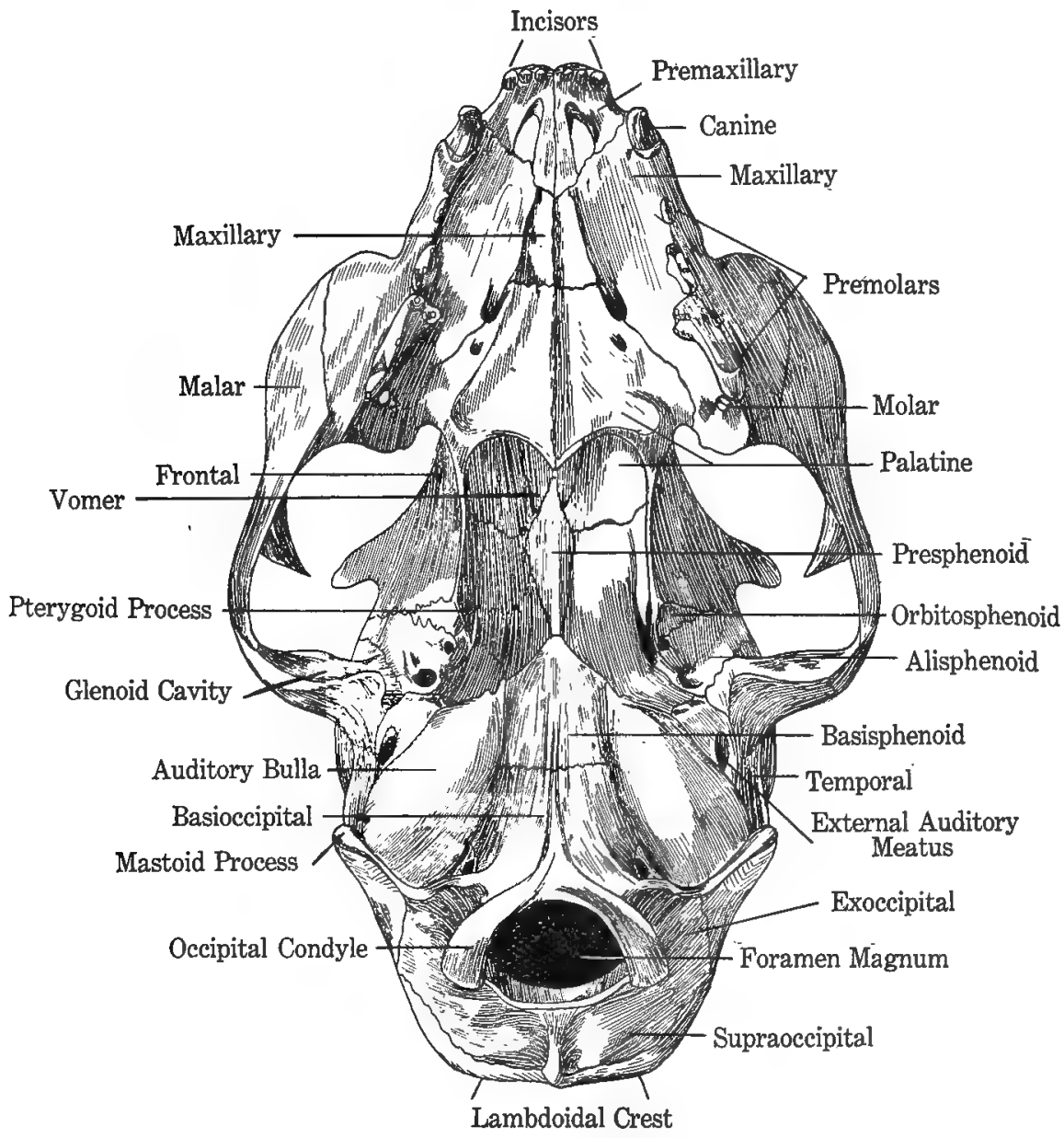

Fig. 5. Ventral Aspect of the Cat's Skull.

(13). Drawing of a crown of a molar. Compare with No. 8.

(I4). Drawing of the ventral aspect of the animal.

(I5). Drawing of the crown of a molar. 
(r6). Examine the cephalic and the caudal aspects of the incisors. How do they differ from those of other rodents?

(21). Compare the crown of the molars with those of Nos. 8 and I 3 .

(3). Draw the lateral aspect of the skull to show the roots of the molars. 







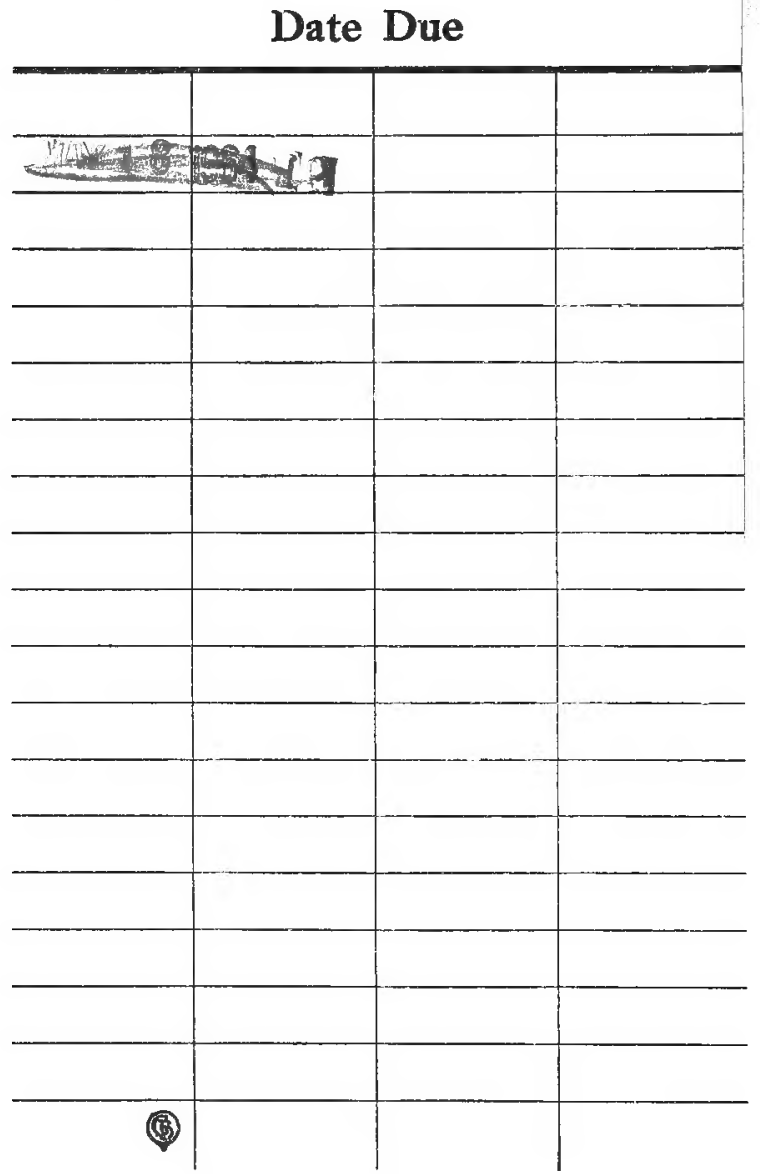




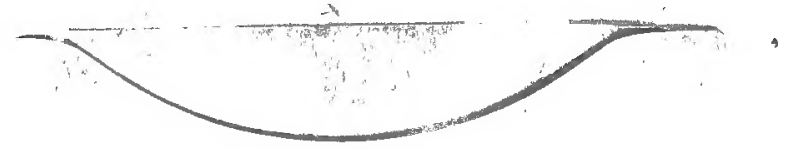

No.

QL 52

R 25

Name Reed and Wright

Address Laboratory outlines ...

2.6271 
$y^{2}+4=0$

(1) $-4 x-x=2 x$ a is 31 tot

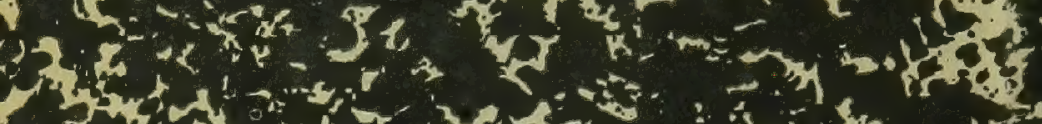

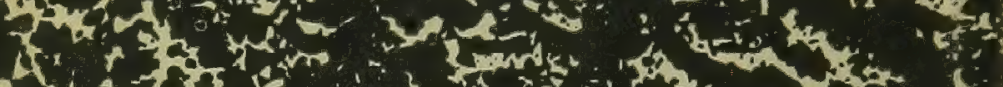

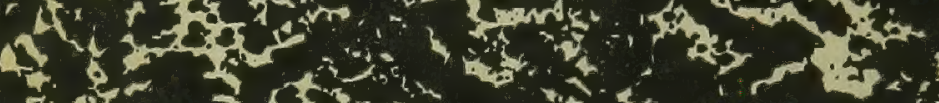
tor 7 son

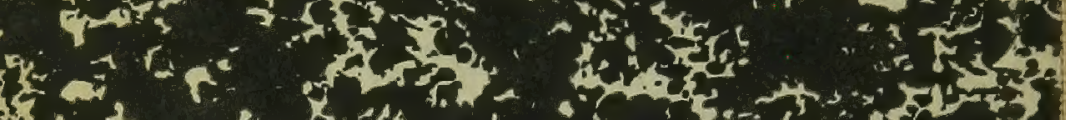

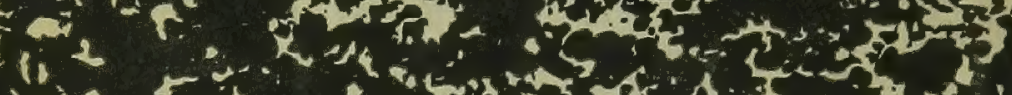
(ind a 120

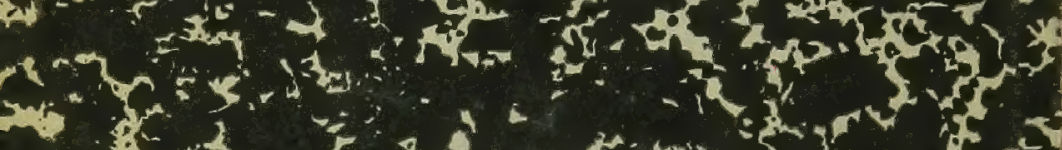

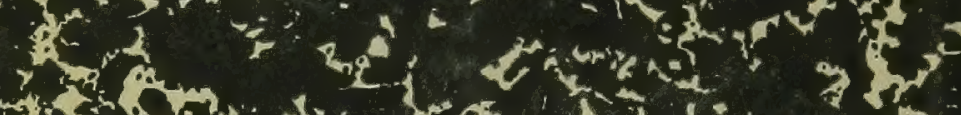

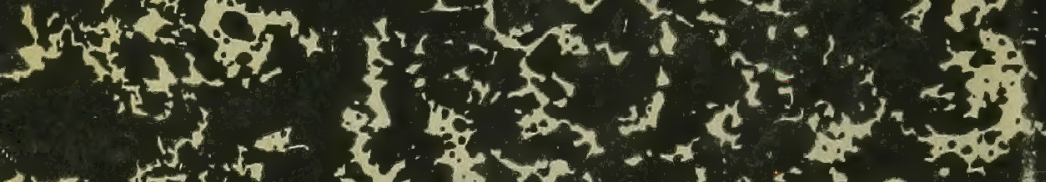

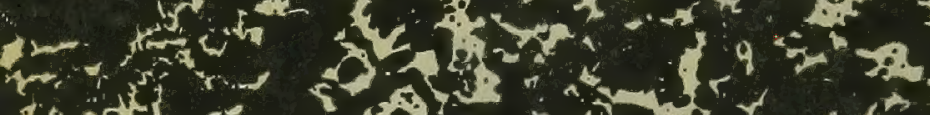

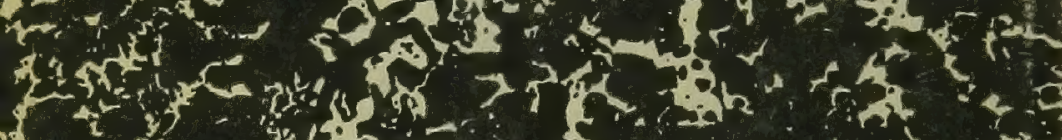

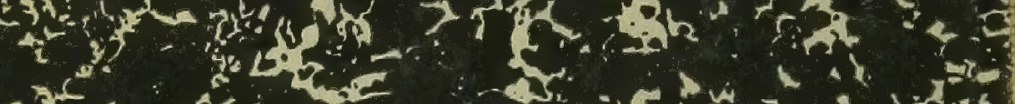
$-4 x-3=0$

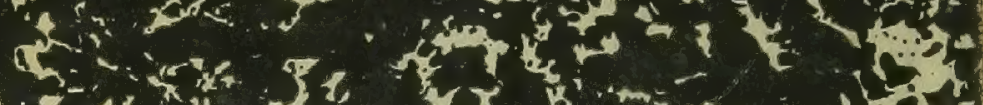

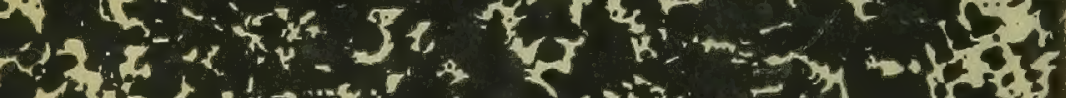

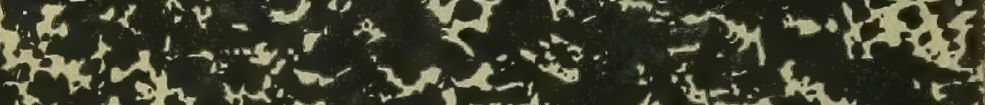

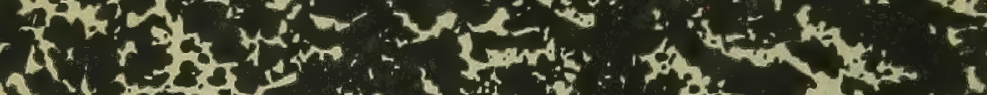

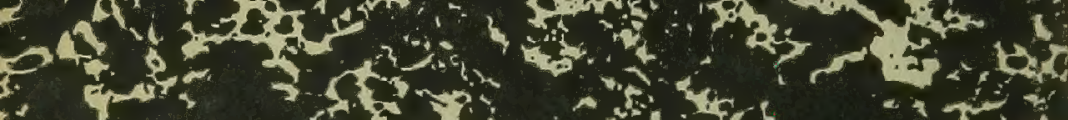
$y=-x+4$ -

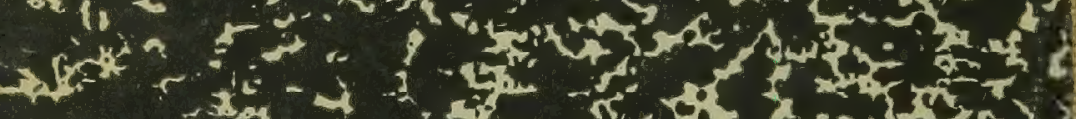

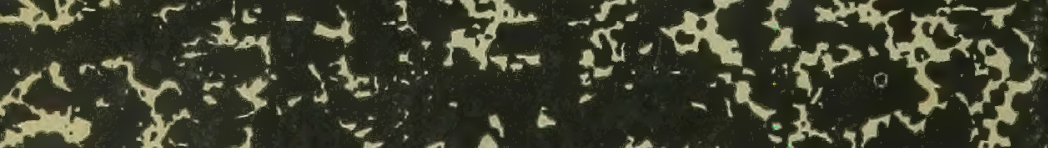

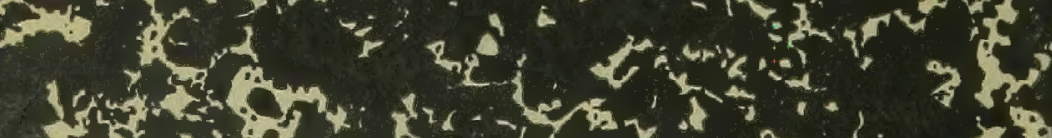

